\title{
OCIO Y CULTURA: MÁS ALLÁ DEL VALOR ECONÓMICO
}

Virginia L. Arbery*

RESUMEN: En esta conferencia, la autora sostiene la vigencia del concepto filosófico del ocio, de manera vertebral en la Academia, y describe cómo el utilitarismo económico ha falseado la jerarquía de valores con respecto a la cultura de Occidente. Al final, se recupera la idea de la tradición y la memoria.

$$
\text { rose }
$$

\section{LEISURE AND CULTURE: BEYOND ECONOMIC UTILITY}

ABSTRACT: In this talk, the author supports the significance of the philosophical concept, leisure, its linear importance in University, and describes how economic utility has distorted the hierarchy of values in Western culture. Finally, she proposes the redemption of the idea of tradition and memory.

PALABRAS CLAVE: ocio, cultura, utilitarismo, tradición, memoria.

KEY WORDS: leisure, culture, utility, tradition, memory.

RECEPCIÓN: 16 de julio de 2014.

APROBACIÓN: 4 de agosto de 2014.

* Wyoming Catholic College. Discurso presentado el 18 de octubre de 2013 en el Instituto Tecnológico Autónomo de México. Traducción de Maria Nobile. 
CITAM Derechos Reservados.

La reproducción total o parcial de este artículo se podrá hacer si el ITAM otorga la autorización previamente por escrito. 


\section{OCIO Y CULTURA: MÁS ALLÁ DEL VALOR ECONÓMICO}

$M_{i \text { esposo y yo nos sentimos muy }}$ honrados de formar parte del compromiso de esta institución con el estudio de las humanidades. Ésta es nuestra primera visita a nuestro gran vecino del sur, con el cual compartimos fuentes culturales y nos identificamos de tantas maneras. Conscientes de la responsabilidad de dirigirnos a los estudiantes del ITAM, espero promover su interés por las humanidades. Sus estudios en contabilidad, ingeniería, economía, computación, negocios, estudios internacionales y otras áreas tienen una importancia práctica incuestionable. Esta institución reconoce que sus estudios profesionales afectarán nuestra cultura positivamente en multitud de aspectos. Al mismo tiempo, nuestra cultura se beneficia de aquellos jóvenes profesionales que han dialogado con Sócrates, escuchado a Aristóteles, padecido con Edipo y, junto con Antígona, se enfrentaron a los Creontes de este mundo: jóvenes que se han recreado, junto con Agustín, en esa "belleza tan antigua y tan nueva". Esta mañana, confío en que aceptarán el motivo de mi discurso. Planeo diagnosticar un síntoma de enfermedad en nuestra cultura: la exclusiva primacía del valor económico. Hacia el final de mi presentación, hablaré del reciente libro de Michael J. Sandel, profesor de estudios de gobierno en Harvard, intitulado Lo que el dinero no compra: los límites morales de los mercados. ${ }^{1}$

${ }^{1}$ Michael J. Sandel, What Money Can't Buy: The Moral Limits of Markets, 2012, New York, Farrar, Strauss \& Giroux. 
Este libro recopila multitud de ejemplos sobre la forma en que la modificación en masa de nuestras vidas frecuentemente las degrada y en ocasiones las corrompe. La asignación de valores monetarios a aquello que por su naturaleza es primordial e incluso sagrado es tan prevalente que difícilmente lo reconocemos ya. Hemos pasado ya el escándalo. Sin embargo, este síntoma, aunque crónico, no necesariamente resulta fatal para nuestra cultura. Puede ser remediado mediante una revisión de la concepción clásica de que el ocio es la base de la cultura. Protegiendo aquello en el ámbito del ocio, la universidad debe aceptar su llamado a la sanación. Permítanme proveer algunos antecedentes, tanto históricos como personales.

En la década inmediata posterior a la Segunda guerra mundial, cuando Europa trabajaba frenéticamente en la reconstrucción del orden social, el filósofo Josef Pieper escribió un libro intitulado Ocio: la base de la cultura. ${ }^{2}$ En él observó que en este esfuerzo hercúleo de reconstrucción, los ciudadanos del mundo occidental estaban poniendo en riesgo los fundamentos que permiten florecer a una vida humana libre. Al redefinir los estándares del trabajo, el júbilo, la festividad y la vida contemplativa fueron depreciados. Pieper observó que en la reconstrucción del mundo material, los europeos estaban perdiendo el aprecio por el ocio que protegía la vida interior de los hombres y mujeres libres. El ruido de los rascacielos en construcción atontaron los sentidos, en tanto que el silencio fructífero que restaura la vida, silencio nutrido por el ocio, quedó en vías de extinción.

Tal vez es atrevido por mi parte hablar acerca del ocio; he enseñado en la universidad por cuarenta años; muchos de estos años, no tuve oportunidad de descanso. Durante las actividades como madre de varios hijos, frecuentemente me encontraba murmurando un verso de un poema de Ogden Nash, “Oh deber, ¿por qué no sois dulce ni tierno?” Si alguien me hubiera preguntado entonces -y sólo alguien verdaderamente grosero lo haría- “¿Tienes mucho tiempo libre?”, hubiera tenido que responderle, “Estás loco?” Cualquiera sabría que tenía poco tiempo libre;

${ }^{2}$ Josef Pieper, Leisure, the Basis of Culture, 1952 (rev. 1964), New York, Pantheon Books, transl. by Alexander Dru. 
sin embargo, siempre consideré como un regalo aquel espacio para el pensamiento, la reflexión, la cavilación. El salón de clases era mi lugar de recreo. ¿Quién me hubiera creído?

Cuando leí el libro de Pieper en el posgrado, aprendí que la palabra griega para cultura, paideia, proviene de la misma raíz que niño y juego. Fue una pieza de información que me liberó y transformó mi obsesión estudiantil por el trabajo arduo y las calificaciones en un gusto por el reino del juego. Seguramente ustedes prefieren el ocio al trabajo; como la mayoría de los estudiantes, probablemente asocian el ocio con el fin de semana o las vacaciones. Sin embargo, por ocio no me refiero solamente a la diversión, la relajación al entretenimiento. No, éstos son escapes del trabajo, planeados para regresar a las actividades con mayor energía; el ocio motivo de mi plática es permanente, generoso y liberador. Es el tipo de ocio crítico para el éxito académico, para nuestra realización personal y para la salud de la cultura. Es la visión clásica y medieval del ocio, posiblemente desconocida para ustedes, ya que postula que ser estudiante no significa estar ocupados, fatigados, apesadumbrados con tareas y deberes. Aprendí que el ocio, no el trabajo, estaba en el centro de la empresa humana. La afirmación de Aristóteles, "trabajamos para el ocio" parece ajena - incluso inmoral, si confundimos su interpretación como "vivimos para el fin de semana". Él se refiere a la contemplación, a la vida filosófica imposible sin el ocio. Aún la participación en la vida política era posible sólo para aquellos libres, educados en las humanidades, liberados de la carga de los trabajos manuales o serviles. En efecto, la palabra griega para ocio, sjole, es la misma palabra en inglés para escuela; así, el trabajo escolar es trabajo de ocio y permite la libertad de pensar acerca del bien común.

Debemos hacer una pausa momentánea para pensar acerca del pensamiento. La Edad media dividía el pensamiento en el ejercicio de la ratio, el pensamiento discursivo y lógico, y el intellectus, la intuición, la capacidad divina en el hombre de ver cosas como son por dentro. Como escribe Piper, el intellectus es "aquella visión simple en que la verdad se ofrece al ojo como un panorama". ${ }^{3}$ La ratio es más activa, es una

${ }^{3} I b i d .$, p. 11. 
capacidad humana, en tanto que el intellectus, o intuición, requiere receptividad y atención a lo dado, ambos existiendo en un mundo "más allá de la esfera de las capacidades humanas". "No," nos dicen los pensadores modernos, objetando al intellectus como modo de conocimiento. Ellos dicen que el conocimiento real es útil; las intuiciones, afirman, producen mundos de fantasía que no nos ayudan a dominar la naturaleza y la política. En su lugar, debemos ser productivos, trabajar duro y, como John Locke escribió, la productividad es la medida de nuestra humanidad. Aún la virtud y el pensamiento deben ser difíciles, enseñó Kant, y, de no serlo, no serían genuinos. Pieper contrapone estas interpretaciones con la de Santo Tomás: "La esencia de la virtud es el bien y no la dificultad". La lectura de la poderosa respuesta de Pieper a esta ética integral del trabajo me llevó a comprender que "la más profunda implicación del exagerado valor que se atribuye al trabajo arduo pudiera ser la siguiente: el hombre parece desconfiar de todo aquello que se obtiene sin esfuerzo; sólo puede disfrutar, en conciencia, de aquello que ha adquirido mediante el trabajo arduo y difícil, rehusándose a aceptar algo regalado". 5

Quiero tomarme unos minutos para considerar el significado de este regalo. En primer lugar, todos estamos de acuerdo en que ser estudiante implica labores, pero que son distintas del trabajo, el cual reduce las metas intelectuales a la simple realización de tareas, aun de manera excelente. El regalo del aprendizaje no debe ser una tarea, una experiencia terrible. Si no son confiables tanto la intuición (intellectus) como la virtud, entonces la belleza y las inmerecidas verdades, por las cuales la humanidad ha vivido y por las que algunos han muerto, son estúpidas e incluso motivo de confusión. Junto con Creonte, debemos descartar la ley divina de Antígona como un simple desafío y dejar a su hermano sin sepultura para ser comido por las aves. Con Critón, deberíamos persuadir a Sócrates a sobornar a sus carceleros y escapar a Tesalia, en lugar de sufrir la injusticia del veredicto ateniense. Con Kant, deberíamos corregir a los pensadores románticos que apreciaron el que

${ }^{4}$ Ibid., p. 12.

${ }^{5}$ Ibid., p. 18. 
"la ley consiste en que la razón adquiere sus propiedades mediante el trabajo". ${ }^{6}$ Así, una actitud esclavista y antiliberal propone que sus grandes metas son "serias", todo pensamiento auténtico es etiquetado como "trabajo intelectual" y los regalos inmerecidos de los altos pensamientos y acciones son denegados, porque uno no puede argumentar legítimamente el haberlos adquirido con arduo trabajo.

En su maravilloso libro El regalo: la creatividad y el artista en el mundo moderno, Lewis Hyde ofrece algunas distinciones útiles entre trabajo y labor. " "Trabajo es lo que hacemos por hora". Por ello, es regido por el tiempo. Es usualmente hecho por dinero. "Trabajo es una actividad intencional llevada a cabo por la voluntad". ${ }^{8}$ Labor, en contraste, aunque pudiera generar un honorario o asignársele un valor monetario, no es sujeto de cuantificación. Nosotros laboramos al crear un poema, al moldear una vasija, al componer una sonata o al descubrir la teoría de cuerdas. "Las cosas se hacen, pero frecuentemente tenemos la extraña sensación de que nosotros no las hicimos". ${ }^{9}$ Bien pudimos estar dormidos cuando el poema fue terminado o cuando la vasija tomaba el acabado perfecto. Frecuentemente despertamos viendo lo que nuestro pensamiento en el día y nuestros esfuerzos no pueden revelarnos. Hyde nos muestra cómo la labor ocurre en una economía gratuita, opuesta a la del intercambio (economía monetaria).

La labor gratuita es el punto intermedio en la transferencia de un regalo. Es enteramente distinta de la "obligación" que sentimos cuando aceptamos algo que en realidad no queríamos. (Una obligación puede ser liberada por un acto volitivo). Un regalo que tiene el poder de cambiarnos despierta una parte del alma. Pero no podemos recibirlo hasta que estamos en capacidad de encararlo como a un igual. Entonces nos sometemos a la labor de convertirnos en un símil del regalo. ${ }^{10}$

${ }^{6}$ Ibid., p. 10.

${ }^{7}$ Lewis Hyde, The Gift: Creativity and the Artist in the Modern World, 1979, New York, Vintage Books (reimpr. 2007).

${ }^{8}$ Hyde, op. cit., p. 63 y 64 resp.

${ }^{9}$ Ibidem

${ }^{10}$ Ibid., p. 65. 
Después de recibir el regalo y esforzarnos por igualarlo mediante la labor de gratitud, estamos listos para actuar en reciprocidad.

Así, en lugar de contabilidad, estados financieros y utilidades económicas, los frutos de la economía gratuita son la libertad, la generosidad y en ocasiones la magnanimidad. Comparemos las dos: una sólida ética de trabajo nos impulsa a ser exitosos. Bien. Nuestra cultura premia el éxito. Estupendo. Sin embargo, la mayoría de las universidades, ignorando la "labor de gratitud", eliminan los textos clásicos de los temarios, cerrando la puerta a momentos transformacionales que por siglos han despertado a las mentes y corazones - han bloqueado el ascenso del neófito por la escalera del amor de Platón y han cerrado los ojos de los estudiantes universitarios, que nunca sentirán lástima por el ciego Edipo, cuya aceptación del sufrimiento lo lleva al conocimiento. Tomando otro ejemplo de sus propios planes de estudio, si los estudiantes no se imaginaran nunca más las conversaciones entre Agustín y Mónica cuando admiran su jardín en Ostia, un conocimiento espiritual y una rica parte de nuestra herencia cultural serían ignoradas.

En mi opinión, debemos admitir que hay un problema particular en las democracias al seguir el modelo kantiano de la ratio y del trabajo intelectual. Como el filósofo político Harry Jaffa observó en una ocasión, un pueblo democrático frecuentemente confunde sus deseos con sus necesidades. Nos podemos preguntar entonces si, cuando la mente se enfoca en la mercadotecnia, pensamos demasiado acerca de lo que deseamos o queremos que otros deseen. Los políticos nos venden deseos como si fueran necesidades y nuestra vida cultural crece bajo la agitación y la impaciencia. Nos volvemos el proletariado en nuestras preocupaciones, en tanto que nuestras aspiraciones intelectuales y espirituales se reducen y nivelan, perdiendo cualquier dimensión vertical que nos pudiera llamar más allá de nuestras necesidades y deseos, un llamado que cuando era escuchado daba a nuestra cultura sus héroes, santos y amantes. Podemos traer a colación una observación que Ignacio de Loyola en el siglo XVI formuló con un lenguaje más vívido que el de nuestros contemporáneos: "hasta los santos de nuestros días hablan en un lenguaje menos radiante: y la santidad se muestra 'con los rayos 
cortos' a través de la neblina negra del utilitarismo universal, el materialismo que los hombres han metido en los pulmones de su propia alma". ${ }^{11}$ Ascetismo, sacrificio y libertad espiritual en oposición a la adquisición, seguridad y fortuna serían signos de una salud cultural restaurada.

Podemos preguntar con razón si la Academia se ha vendido a los productores de bienes tangibles, empresas, y aptitudes de tal forma que se resigna a ser propiedad del mundo, en sus términos. Si es el caso en 2013 -y hay buenas razones para pensarlo-, entonces un plan de estudios verdaderamente humanístico resulta contra cultural. Cuando un plan de estudios se rehúsa a ser sujeto de la presión del utilitarismo económico, algunos pudieran aducir que está fuera de lugar, que es impráctico y de poco valor, irresponsable incluso. Yo refutaría diciendo que el utilitarismo económico es el enemigo de la libertad académica. Cuando la Academia cumple con su alto propósito, genera admiración en sus estudiantes - porque, como Aristóteles escribe, la admiración es el acompañante de la poesía y de la filosofía. La guía que ellas proveen al orden humano sobrevivirá a las crisis de las economías globales y a la obsolescencia tecnológica. ¿Y quién, pregunto, será capaz de entender e imaginar cómo guiar a la sociedad si la escala de vida rebasa al bien humano, como ocurrió en algún momento en Roma y posiblemente ya nos ocurre? La Academia no debería ser el peón de aquellos que la utilizan sólo para producir trabajadores en sus empresas. Los líderes universitarios no pueden "permitirse" ser tan cortos de miras, porque si no pueden proteger a la alta educación de ser manipulada por las fuerzas económicas, la universidad se colapsará con ellas. La Academia debe ver por las cosas permanentes o perecer junto con las temporales.

A menos de que el pensamiento salga del nivel proletario en que lo hemos colocado, nuestra humanidad está en riesgo. Mi premisa de colocar a la Academia fuera del utilitarismo económico está guiada por los comentarios aristotélicos en la Política, donde se dice "buscar en

${ }^{11}$ Apud Cardinal Bourne, "Preface", The Autobiography of Soeur Therese of Lisieux, The Story of a Soul, $1912^{8}$ (1922), London, Burns, Oates \& Washbourne, edit. by rev. T. N. Taylor. 
todos lados el elemento utilitario es lo que menos corresponde a aquellos magnánimos y libres". ${ }^{12}$ Nuestras instituciones académicas deben reconocer que los estudiantes son libres. Sólo una educación liberal provee el espacio para la inspiración y la revelación de lo que William Faulkner llamó "las verdades" en su discurso de aceptación del premio Nobel-amor y hondura y piedad y orgullo y sacrificio. "Hasta que el joven hombre o mujer que escribe hoy reaprenda estas cosas, escribirá como si estuviera presenciando el fin de la humanidad", escribió Faulkner en 1950. Agregaba: "yo me rehúso a aceptar el fin de la humanidad [...] yo creo que el Hombre no solamente sobrevivirá: prevalecerá, pues es inmortal, no porque de entre todas las creaturas él tenga una voz infatigable, sino porque tiene un alma, un espíritu capaz de compasión, sacrificio y resistencia". ${ }^{13} \mathrm{Al}$ comprometerse con la lectura de los textos clásicos, la Academia puede transmitir estas verdades y restablecer las miras de nuestra cultura más allá del utilitarismo económico.

Reconozco que he hecho serias acusaciones sin clarificar el significado de utilitarismo económico. Entre los antiguos, Epicuro construyó su filosofía alrededor de una visión utilitarista. No concibió una visión de la vida más allá del aquí y el ahora, un presente pacífico libre de miedo y dolor. Pero es Nicolás Maquiavelo quien introduce, como él dice, "nuevas formas y órdenes", que han sido llamados el proyecto moderno. Me referiré brevemente a él y a dos pensadores ingleses que siguen su pauta. Maquiavelo, por supuesto, asegura a su príncipe que el deseo de adquirir es una cosa natural y ordinaria. No hay un telos o fin apropiado del deseo. Recordarán que Maquiavelo declara en su capítulo XV que, hasta su enseñanza, aquellos que han buscado repúblicas ideales han sido incapaces de producir una "verdad eficaz". En el Príncipe el único pecado es ser ineficaz. Él rechaza claramente la síntesis clásico-medieval, la "Ética antigua” por sus "nuevas formas y órdenes". El "debiera", que sólo existe en la imaginación, dice, es remplazado por "lo que es" o "lo útil". ¿Y qué es útil? Lo que funciona. Su regla prudencial es "hacer el menor mal como bien en tanto sea

${ }^{12}$ Arist. Pol., 1338 b1.

${ }^{13} \mathrm{http}$ //www.nobelprize.org/nobel_prizes/literature/laureates/1949/faulkner-speech.html 
conveniente". ${ }^{14}$ Un líder prudente no necesita estar atado por sus promesas. Al mismo tiempo, debe parecer virtuoso en el sentido antiguo. El soporte de tal enseñanza amoral es que "si todos los hombres fueran buenos, esta enseñanza no sería buena; pero al ser malvados y no tener fe en ti, tú tampoco debes tenerla en ellos". La vieja ética es simplemente inaplicable para Maquiavelo. Sólo un líder irresponsable consideraría a Platón, Aristóteles o a santo Tomás.

Thomas Hobbes en su Leviatán también rechaza la ética aristotélica, junto con su política y metafísica. Su psicología socava el amor de lo noble por sí mismo, exponiéndolo como una ficción que oculta al verdadero objetivo: el poder. El deseo del hombre por el poder va de la mano con su deseo de paz. La paz asegura aquello que cada persona busca adquirir mientras les permite evitar aquello que temen producirá dolor. El hombre de Hobbes es calculador, no elevado. "Para él, los pensamientos son a los deseos, exploradores y espías que atisban más allá y encuentran el camino a las cosas deseadas". ${ }^{15}$ Los pensamientos son sólo muestra de los deseos. Pero este proceso de búsqueda de lo que uno desea es interminable, dado que alcanzar un objetivo solamente lleva a la búsqueda del siguiente. Entonces, la "felicidad" no tiene conclusión y estamos en constante movimiento, sin descanso en su búsqueda. Thomas Spragens, en su estudio concienzudo del Leviatán llama a esto una "carrera de codazos". ${ }^{16}$

Al examinar otro gran pensador inglés descendiente de Maquiavelo, Robert Goldwin explica esta nueva ética en los escritos de John Locke de la siguiente forma: "Locke, debe decirse, no niega explícitamente la importancia de la excelencia o del amor; simplemente las ignora [...] Lo que cuenta es lo universal y poderoso, que existe con fuerza controladora dentro de todo hombre y es lo que podemos confiar que gobernará su comportamiento [...] Debe admitirse que los hombres

${ }^{14}$ Niccolo Machiavelli, The Prince, 1998, Chicago, University of Chicago Press, transl. by Harvey C. Mansfield, Jr., p. 62.

${ }^{15}$ Thomas Hobbes, Leviathan, 1944, Indianapolis, Hackett Publishing Company, ed. by Edwin Curley, p. 41.

${ }^{16}$ Thomas A. Spragens Jr., The Politics of Motion: The World of Thomas Hobbes, 1973, Lexington, The University Press of Kentucky. 
tienen derecho a hacer aquello que es imposible no hacer". ${ }^{17}$ Los hombres productivos desean tener cosas, más posesiones, más propiedades, $\mathrm{y}$ asegurarlas a través del gobierno. Incluso un obrero, con salarios mínimos, está mejor y es más valioso en su productividad que el indio que habita las planicies de América. Reflexionando en el esquema de Locke, Leo Strauss observó que produce una "infeliz búsqueda de la felicidad".

Hay un camino muy corto entre el miedo al dolor de Hobbes, el énfasis de Locke en la obtención de propiedades y el utilitarismo de Bentham. El pensamiento dieciochesco de Jeremy Bentham y sus acólitos del siglo diecinueve, James y John Stuart Mill, dieron al utilitarismo su nombre y filosofía. Después de repasarlo brevemente, los dejaré pensar por su cuenta cómo podrían responder ustedes. Podrán encontrar su pensamiento muy atractivo, razonable e incluso evidente. Por otro lado, ustedes podrán juzgarlo como una filosofía de gobierno de nuestra cultura, signo preocupante de su naturaleza esclavista. En cualquier caso, me parece que debemos rebasar al utilitarismo económico; el remedio comienza cuando laboramos para aceptar el regalo de ser seres libres. Para llevarlo a cabo, requerimos rechazar los límites autoimpuestos por la búsqueda de bienes instrumentales (objetivo utilitarista): entonces podemos extirpar lo que Jeremy Bentham llamó el "imperio" del placer y del dolor, nuestros "dos mayores soberanos".

Jeremy Bentham comienza su Introducción a los Principios de la Moral y la Legislación, con la siguiente afirmación: "La Naturaleza ha ubicado a la humanidad bajo el gobierno de dos soberanos mayores, el dolor y el placer". ${ }^{18}$ Siguiendo a Hobbes, establece sus bases para la elección ética: "Les corresponde a ellos (placer y dolor) y sólo a ellos determinar qué deberíamos hacer y qué haremos". Bentham afirma que el principio de utilidad reconoce esta sujeción, y la supone en los fundamentos de ese sistema, cuyo objeto es levantar la fábrica de la felicidad con las manos de la razón y la ley. Sistemas que tratan de cuestionarlo, emplean sensaciones en lugar del sentido, capricho en lugar

${ }^{17}$ Robert A. Goldwin, “John Locke”, The History of Political Philosophy, 1963, Chicago, University of Chicago Press, ed. by Leo Strauss \& Joseph Cropsey, p. 441.

${ }^{18} \mathrm{http} / /$ www.utilitarianism.com/jeremy-bentham/, todas las referencias sobre Bentham provienen de este sitio. 
de razón y obscuridad en lugar de luz. La "fábrica de la felicidad" o felicidad, que en el sentido aristotélico es la armonía del alma con su propia excelencia, es reducida al principio de que las decisiones de los seres humanos están regidas por su búsqueda del placer y por evitar el dolor. En contraste, Aristóteles observa que los hombres en efecto interpretan el bien como lo que es placentero o útil; coloca al placer y al dolor debajo del amor por lo noble y lo noble por debajo de la vida contemplativa. La mayoría de la gente "se muestra completamente doblegada al escoger una vida que pertenece al ganado gordo". Añade que recibir honores (como los políticos), depende de quienes los otorgan, "pero sabemos que el bien es algo propio de uno y difícil de quitárnoslo". ${ }^{19}$ Pero para Bentham, obedecer a los dos amos, placer y dolor, asegura que uno actuará racionalmente y acorde con la naturaleza.

En esta secuencia de pensadores modernos, James Mill y su hijo John Stuart Mill defienden a Bentham de sus críticos, que alegan que Bentham elimina tanto filosofía como belleza. El credo de los Mill "acepta como fundamento de la moral, la Utilidad o Principio de la Mayor Felicidad". Mill protege el pensamiento de Bentham como Cerbero protege las puertas del infierno. Comienza su intento de justificar el utilitarismo insistiendo que Bentham no reduce el placer humano a la vida de los cerdos; en su intento de justificación, sin embargo, cae en un error más grave. Su respuesta a los adversarios de Bentham es que de dos placeres uno debe cualitativamente ser mejor que el otro, porque "todos o casi todos los que han experimentado ambos tienen establecida una preferencia, sin considerar ningún sentido de obligación moral de preferir alguno". ${ }^{20}$ Para Mill, entonces, aún sin una guía ética, existe una jerarquía de placeres. Pero ahí está el problema: dicha jerarquía está determinada por la corte democrática; lo que es juzgado por la mayoría de los hombres como mejores placeres es decisivo. ¿Pueden ver cómo este relativismo de placeres no está asido a nada salvo a la opinión, como en la caverna de Platón? Una vez dentro de ella, no hay un camino de salida, ningún estándar más allá de lo que la mayoría consi-

\footnotetext{
${ }^{19}$ Arist. EN, 1095b.

${ }^{20} \mathrm{Cfr}$. Bentham, op. cit.
} 
dera placentero y digno de búsqueda, o doloroso y por ello justificadamente evitable. La caverna se vuelve una burbuja impenetrable y sellada. Como escribió el crítico de Mill del partido de los "whig", Thomas Babington Macaulay, los utilitaristas “ceden su comprensión [...] a los más groseros e insostenibles sofismas, suponiendo que se muestran disfrazados como los elementos de una demostración. Ellos no parecen entender que la lógica, al igual que la retórica, tiene sus ilusiones; la falacia puede alojarse tanto en un silogismo como en una metáfora". ${ }^{21}$

Para ser justos, los dos Mill insisten en la dignidad de los hombres que prefieren, aun cuando no sea placentero escoger un camino digno. A ellos les gustaría preservar lo noble de aquellos pocos sentimientos que pueden motivar el sacrificio y el soportar dolor por un placer mayor al dinero y el premio de los sentidos. Incluso les gustaría un mundo donde Sócrates no fuera forzado a tomar la cicuta; sin embargo, ningún de los Mill proveen un orden ontológico o base metafísica para esta conducta, salvo decir que algunos hombres prefieren placeres mayores aun cuando impliquen dolor conseguirlos, implicando así cómo los animales son inferiores al hombre.

Sabemos por el pensamiento de Richard Rorty, John Rawls y otros filósofos del siglo veinte que la defensa del utilitarismo de James Mill no puede sustentar lo que él mismo reconoce como altas facultades del hombre. Como cabe esperar, la lógica de su pensamiento lleva a la dominación cultural de la tiranía mayor, que en términos de Tocqueville constituye la mentalidad de masa. Un signo de esta fijación en la igualdad es la incapacidad de su filosofía de distinguir entre distintos tipos de paradigmas éticos. Rorty y Rawls, si entiendo bien su razonamiento, concluyen que lo que mejor funciona es el pluralismo, el último revestimiento de la democracia, implicando el fin de la sociedad civil. En su visión, los distintos grupos e intereses se amalgaman alrededor de algún tipo de acuerdo, sin basarse en una ley superior o verdades evidentes. Ésta es la única solución práctica a tantos problemas éticos. Pero estos argumentos, al observarlos detenidamente, se muestran como máscaras para el placer y el dolor, deseos disfrazados de necesidades. John Stuart Mill, sospecho, estaría desilusionado por

${ }^{21}$ http://plato.stanford.edu/entries/james-mill/ 
esta disminución del pensamiento político, pese a su confianza en la "marcada preferencia" por algunos de los placeres de la vida intelectual. Sonando casi aristotélico, Mill se queja de la capacidad de los jóvenes de participar en la política sin una previa formación en las virtudes. Continúa diciendo que "el ser capaz de los sentimientos más nobles es como una planta tierna y fácil de matar [...] en la mayoría de las personas esta planta muere rápidamente si las ocupaciones que les requiere su estatus social [...] no son favorables para ejercitar esta cualidad mayor. Los hombres pierden sus aspiraciones mayores [...] porque no tienen el tiempo o la oportunidad de permitírselas". ${ }^{22} \mathrm{Al}$ reconocer la importancia del hecho de que los jóvenes tengan el tiempo y el lugar disponibles para la vida contemplativa -llamémosle Universidadaún Mill, el sofista defensor del utilitarismo, revela una persistencia de las preferencias antiguas que irónicamente trata de mermar en su defensa de Bentham.

Habiendo repasado ya algunas de las influencias intelectuales en nuestra preferencia cultural por la utilidad económica, me gustaría pasar a algunos ejemplos de la mentalidad que ha producido en nuestra cultura. Dado el componente de artes liberales en su educación, los supongo preparados para determinar por qué estos enfoques son cuestionables. Espero que puedan intuir cómo el recuperar una disposición por el ocio en el sentido clásico-medieval puede ser una cura para esta enfermedad.

El estudio de Michael Sandel que les mencioné al inicio de esta disertación ilustra cómo la teoría económica contemporánea busca superar todo obstáculo irracional al utilitarismo. ${ }^{23}$ Sandel argumenta que en nuestra cultura las ganancias económicas buscan "colonizar todo aspecto de la vida". ${ }^{24}$ Restringiré sus ejemplos a sólo tres áreas: matrimonio, hijos y ciudad o polis. Estos son los tres niveles de asociación o colaboración descritos en la Política de Aristóteles. El principio rector en todos estos ejemplos es que no hay nada tan sagrado que no pueda ser comprado y vendido, es decir, al que no se le pueda asignar un valor de mercado.

\footnotetext{
${ }^{22} \mathrm{http} / /$ www.carroll.edu/msmillie/perspectives/millutilch2.htm

${ }^{23}$ Sandel, What Money Can't Buy..., op. cit., p. 103.

${ }^{24}$ Ibid., p. 179.
} 
Comencemos con el matrimonio. Sandel cita el argumento de Gary Becker en El enfoque económico a la conducta humana de 1976, quien rechaza "la noción de que la economía es el estudio de la asignación de bienes materiales". ${ }^{25}$ Eso está pasado de moda. Sandel evalúa esta forma de pensar que reduce todos los aspectos de la vida a lo que llaman la economía de la utilidad: "En todos los aspectos de la vida, la conducta humana puede explicarse suponiendo que las personas deciden qué hacer, sopesando los costos y beneficios de las opciones que se les presentan, y escogiendo aquella que esperan les provea del mayor bienestar o utilidad". ${ }^{26}$ Las personas tratan de maximizar su beneficio sin importar el contexto. "Esto aplica tanto para escoger pareja como para comprar una lata de pintura". Si los hombres y las mujeres no perciben sus relaciones de esta forma, es simplemente porque están ciegos a sus verdaderas motivaciones. Aquellos más observadores, escribe Sandel resumiendo a Becker, "pueden ver que toda nuestra conducta, por más ajena a los intereses materiales, puede ser explicada y predicha mediante un cálculo racional de costos y beneficios" ${ }^{27}$ Déjenme reconocer que los acuerdos prenupciales reflejan un modelo de costo/beneficio, pero me parece un poco más drástico aceptar la afirmación de que en general "una persona decide casarse cuando la utilidad esperada del matrimonio excede a la correspondiente a permanecer soltero o a continuar buscando una pareja adecuada". El divorcio o separación está explicado de manera similar: "una persona casada termina su matrimonio cuando la utilidad anticipada de volverse soltero o casarse con alguien más excede la pérdida en utilidad de la separación, incluyendo las pérdidas debidas a la separación física de los hijos, la división de los bienes materiales, las cuotas legales y demás". Concluye que "dado que hay muchas personas buscando pareja, se dice que existe un mercado de matrimonios". ${ }^{28}$

Me pregunto si la esposa de Becker está satisfecha al considerarse a sí misma como una buena compra o un buen negocio. Qué diferencia existe entre esta degradación del amor y el mercado de esclavos

${ }^{25}$ Ibid., p. 49.

${ }^{26}$ Ibid., p. 48.

${ }^{27}$ Ibid., p. 50 .

${ }^{28}$ Ibidem. 
en Nueva Orleans, donde hermosos cuarterones y octorones fueron vendidos para el placer y el estatus social que tanto buscaban sus compradores. ¿O qué tan diferentes a las novias por correspondencia, tan necesarias en las arduas vidas de los solitarios hombres en el salvaje viejo oeste? ¿Puede en verdad este tipo de análisis utilitarista, que se permea a mi propia disciplina, la ciencia política, explicar la fidelidad de Penélope al esperar por veinte años a Odiseo? ¿Puede explicar cómo mediante las plegarias y el perdón de Mónica, la madre de Agustín, pudo domesticar y convertir a su abusivo esposo? ¿Puede este análisis de costo-beneficio de Becker satisfacer a los lectores de la Tempestad de Shakespeare, cuando observan el amor de Fernando por Miranda, o pueden analizar adecuadamente la belleza y el amor mutuo y duradero de Kitty y Levin en el Ana Karenina de Tolstói, entre incontables ejemplos de las dimensiones del amor? Becker nos diría que las descripciones de grandes amores ficticios o verdaderos matrimonios sin interés satisfacen un sentimentalismo falso. La tradición del cortejo, la tradición de la dama, el poder del corazón, el primer órgano que se desarrolla en el bebé dentro del útero, de alguna forma no tienen cabida en los asientos del balance contable en la mente estéril del economista.

Pasemos a los niños. Las bajas tasas de fecundidad en Europa y ahora en los Estados Unidos, los bebés por diseño, los bancos de esperma, los úteros en renta, los incentivos para la esterilización, la realidad de que, en los Estados Unidos, el 90\% de los bebés con síndrome de Down son abortados, indican que los occidentales en efecto están realizando un análisis de costo-beneficio cuando se trata de tener niños y elegir cuál tipo prefieren. Tal parece que, en el campo de la biología, la capacidad científica de hacer ciertas cosas significa que moralmente son aceptables. Esto me recuerda a la advertencia de Dante en el Infierno (XXVI, 21-24): "Refreno mi talento, para que no corra cuando la virtud no puede guiarlo, de tal forma que si mi estrella o algo mejor me han dado este regalo, no abusaré de él". ${ }^{29}$ En el siglo dieciocho, "Una humilde

${ }^{29}$ Dante Alighieri, The Divine Comedy, 1995, New York, Alfred A. Knopf, transl. by Allen Mandelbaum, p. 170. 
propuesta" de Jonathan Swift sugiere comerse a los bebés para resolver el problema irlandés. Uno puede argumentar que hay poca diferencia entre esa propuesta - escrita con sentido satírico-y lacerarlos o arrancarlos del útero materno. Sandel no toca el tema del aborto, pero sí cuestiona a Richard Posner, un juez estadounidense, prominente en la esfera legal y económica. Posner propuso "el uso de los mercados para asignar bebés puestos en adopción”. Los bebés más deseables tendrían precios más caros. La práctica actual no es económicamente sensata, porque las cuotas de adopción no están basadas en precios de mercado. ¿Por qué no subastar bebés? ¿No suena esto otra vez como el mercado de esclavos? Más contenido que yo, Sandel pregunta a sus lectores lo siguiente: los "buenos" niños huérfanos sobreviven a la venta, ¿pero no resultan todos los niños degradados, corrompidos o afectados en su dignidad?

Kenneth Boulding, un economista que estudié en la universidad sugiere "permisos mercadeables de procreación", algo similar al mercado de bonos de emisión de carbono, y, como Sandel sugiere, lo que ocurrirá es que una vez que los niños se conviertan en un bien de lujo, serán accesibles sólo a los ricos. Déjenme añadir aquí que ahora es bastante común que las parejas calculen cuánto les costará tener y criar a un niño o niños. Esto puede justificarse como prudente y responsable. Pero, ¿qué efecto tendrá el que un niño entienda que vale cierta cantidad, que es producto de un buen cálculo en lugar de serlo del amor y la generosidad? Tantos niños ahora se refieren a ellos mismos como errores, como si sus padres reprobaran el examen de matemáticas $\mathrm{y}$ ahora tienen que sufrir las consecuencias de sus malas cuentas.

Aquellos niños que no llegan al mundo proveen a los anunciantes nuevos campos de explotación. De acuerdo con la teoría de los incentivos, articulada en el libro de texto de Greg Mankiw, "la gente responde a los incentivos", ${ }^{30}$ y la producción es sustentada por incentivos a grupos mayores de la población con disponibilidad de efectivo. Los anunciantes han penetrado los canales de la televisión educativa. Como Sandel escribe, tal publicidad "confunde las fronteras entre lugares y vuelve cada

${ }^{30}$ Apud Sandel, op. cit., p. 85. 
escenario un lugar de venta. "¡Descubre tu propia fuente de ingresos a las puertas de la escuela! Dice un folleto anunciando una conferencia de mercadotecnia para anunciantes en el medio escolar [...] Ya sean niños de primaria aprendiendo a leer o adolescentes comprando su primer auto, podemos garantizar la introducción de tu producto y de tu compañía a estos estudiantes en el entorno tradicional del salón de clases". ${ }^{31}$ En Colorado, nuestro estado vecino, un distrito escolar vendió espacio en los reportes de calificaciones para anuncios publicitarios. ${ }^{32}$ ¿Qué dirían ustedes de ese distrito escolar y de la comunidad que lo permite? ¿Es el entorno escolar sólo una oportunidad más de negocio? ¿Ya no hay libertad para que el estudiante ame el aprendizaje por sí mismo? ¿Debe un estudiante considerarse como un mercado para los adultos? Un niño podría comenzar a deducir, con razón, que su educación no es el tema. Él es, utilizando la frase de Heidegger, "una reserva en espera" del consumo, como los árboles en el bosque son vistos como pulpa para hacer papel. Atrapados en el edificio escolar, ¿son los niños libres o esclavos?

Hay tanto que decir acerca de la asimilación de la vida cívica a los incentivos, mercados y la promoción de fines no cívicos que uno difícilmente sabe por dónde comenzar con los ejemplos. Sandel se preocupa, como todos deberíamos, de que el interés propio dicte la forma en que la esfera pública se conduce, en lugar de la virtud cívica y la voluntad política. Esta visión sustenta que la virtud es escasa, se acaba y así los mercados preservan cuánta virtud permanece por ahí. Sandel cita a Kenneth Arrow: "los economistas típicamente dan por sentado que, dado que un mercado incrementa el espacio de decisiones de un individuo, entonces conlleva mayores beneficios. Así, si a un donante voluntario de sangre le diéramos la posibilidad de venderla, estaríamos solamente expandiendo el rango de alternativas para el individuo. Si él obtuviera toda su satisfacción en el dar, entonces puede seguir dando y nada ha ocurrido que impida su derecho". ${ }^{33}$ Sandel cuestiona si la comercialización de la disposición a dar sangre "cambia el significado

${ }^{31}$ Op. cit., p. 201.

${ }^{32}$ Ibid., p. 199.

${ }^{33}$ Ibid., p. 125. 
de donarla". ${ }^{34}$ El razonamiento es como sigue: es poco factible que el deseo por el servicio público, la generosidad desinteresada, el deseo por la salud de la vida cívica y sus instituciones puedan vencer al interés propio y al beneficio económico; pero si este servicio desinteresado existe, ¿por qué agotarlo? Este enfoque hacia la vida cívica y la participación es la receta para la destrucción de la política, el signo de una cultura enferma. De hecho, la situación es muy diferente. Sandel cita la afirmación de Rousseau: "En una ciudad bien regida, todo hombre se apresura a llegar a las asambleas"; tan pronto como el servicio público deja de ser el principal interés de los ciudadanos -quienes prefieren servir con su dinero que con sus personas-, el Estado no está lejos de su caída". ${ }^{35}$ Respondiendo a los economistas que argumentan que mantienen la participación pública con incentivos, Sandel dice: "el altruismo, la generosidad, la solidaridad y el espíritu cívico no son artículos de comercio que se agoten con el uso. Son más bien como los músculos que se desarrollan y crecen más fuertes con el ejercicio. Uno de los defectos de la sociedad dominada por el mercado es que deja estas virtudes languidecer. Para renovar nuestra vida pública necesitamos ejercitarlas vigorosamente". ${ }^{36}$

Sandel ha descrito precisamente lo que Aristóteles llama energeia, el ejercicio activo del alma de acuerdo con su propia excelencia, un ejercicio vital para la salud de la cultura. Conforme las imágenes y paradigmas de la vida cívica desinteresada continúan desapareciendo, dando paso al enfoque utilitarista de la educación, los jóvenes serán más y más vulnerables a las maquinaciones de otros: oportunistas que han calculado cuán poca virtud tienen pero cuán lucrativo que es su mercado.

Me doy cuenta de que en una parte de mi discurso me he concentrado en lo que llamé la enfermedad de nuestra cultura y en otra he sugerido algunos síntomas. Lo que no he hecho es plantear una solución simple. Y no lo he hecho porque eso no es posible en una verdadera sanación. La cura debe operar en todo nivel de la sociedad. Nosotros, que estamos en la Academia, podemos comenzar al menos protegiendo su integridad

${ }^{34}$ Ibid., p. 126.

${ }^{35}$ Ibid., pp. 128-9.

${ }^{36}$ Ibid., p. 130. 
mediante la restauración de una extremadamente "útil” facultad humana, muy poco utilizada. Afortunadamente, esta gran capacidad humana, como los músculos del cuerpo, crece y se profundiza con el uso. Es la memoria. San Agustín escribió, "el trono de la mente es la memoria". La Academia, en todos sus niveles, debe reubicarse a sí misma en la memoria de la gran tradición del aprendizaje, para que así la mente pueda embarcarse en la "labor de gratitud" que nos hará digna de ella.

Entonces, deberemos engrandecer la tradición, dejarla mejor que como la encontramos al hacerla nueva y propia. 
CITAM Derechos Reservados.

La reproducción total o parcial de este artículo se podrá hacer si el ITAM otorga la autorización previamente por escrito. 